\title{
Efeito de fontes e formas de processamento do amido sobre o desempenho e o metabolismo do nitrogênio em vacas Holandesas em lactação
}

\author{
Alexandre Vaz Pires ${ }^{1}$, Ivanete Susin ${ }^{1}$, Flávio Augusto Portela Santos ${ }^{1}$, Clayton Quirino \\ Mendes $^{2}$, Reinaldo Cunha de Oliveira Junior ${ }^{3}$, Juliano José de Resende Fernandes ${ }^{3}$, \\ José Manuel Correia de Simas ${ }^{4}$
}

\footnotetext{
${ }^{1}$ Departamento de Zootecnia, ESALQ/USP, Av. Pádua Dias, 11, CP 09, CEP: 13418-900, Piracicaba, SP.

2 Doutorando do curso Ciência Animal e Pastagens, Departamento de Zootecnia, ESALQ/USP.

${ }^{3}$ Departamento de Produção Animal, Universidade Federal de Goiás.

${ }^{4}$ Pós-Doutorando Departamento de Zootecnia, ESALQ/USP.
}

RESUMO - Avaliou-se a influência das fontes e formas de processamento do amido utilizado na dieta sobre o desempenho e o metabolismo do nitrogênio em vacas Holandesas em lactação alimentadas com cana-de-açúcar como volumoso. Utilizaram-se cinco vacas pluríparas, canuladas no rúmen e no duodeno, distribuídas em quadrado latino $5 \times 5$. As rações foram compostas de $40 \%$ de cana-de-açúcar e $60 \%$ de concentrado e diferiram quanto ao processamento ou à fonte principal de amido: milho moído grosso; milho moído fino; milho floculado a $310 \mathrm{~g} / \mathrm{L}$; milho floculado a 360 g/L ou raspa de mandioca. A taxa de hidrólise in vitro do amido da raspa de mandioca foi superior à obtida com as demais fontes de amido testadas. O amido do milho floculado apresentou maior taxa de hidrólise em comparação ao amido do milho moído. Os percentuais médios totais de amido hidrolisado foram de 93,5\% para raspa de mandioca, 85,6\% para milho floculado a $310 \mathrm{~g} / \mathrm{L}, 83,7 \%$ para milho floculado a $360 \mathrm{~g} / \mathrm{L}$ e 37,8\% para milho moído. As fontes de amido e seu tipo de processamento não influenciaram o consumo de matéria seca, os teores de gordura e proteína do leite, a síntese microbiana e a concentração plasmática de glicose. A utilização da raspa de mandioca reduziu as produções diárias de gordura e proteína e a produção de leite corrigida para 3,5\% de gordura, cujos valores médios foram de 0,40; 0,45 e 12,48 kg/dia; 0,68; 0,64 e 19,74 kg/dia; 0,57; 0,62 e 17,37 kg para raspa de mandioca, milho floculado e milho moído, respectivamente. A concentração de amônia ruminal foi menor quando fornecidas as rações contendo milho floculado ou raspa de mandioca, o que indica fermentação mais ativa destas fontes de amido. Apesar de apresentar maior taxa de hidrólise do amido, a raspa de mandioca alterou o metabolismo protéico dos animais ocasionando redução da síntese de proteína microbiana.

Palavras-chave: milho floculado, parâmetros sangüíneos, processamento de grãos, produção de leite, raspa de mandioca, síntese microbiana

\section{Effect of starch sources and processing on performance and nitrogen metabolism in lactating Holstein cows}

\begin{abstract}
The objective of this trial was to evaluate the effect of starch sources and processing used in diets on performance and nitrogen metabolism of lactating Holstein dairy cows fed sugar cane as forage. Five multiparous lactating Holstein cows, cannulated in the rumen and proximal duodenum, were used in a $5 \times 5$ Latin square. Cows were fed a 40:60 forage concentrate ration ( $40 \%$ fresh sugar cane and $60 \%$ concentrate) and differ only on processing or mainly starch source: cracked corn; finely ground corn; flaked corn at $310 \mathrm{~g} / \mathrm{L}$; flaked corn at $360 \mathrm{~g} / \mathrm{L}$ or cassava scrapings. The in vitro starch hydrolysis rate of cassava scrapings was higher than others sources of starch in this trial. The flaked corn showed higher hydrolysis rate of starch than ground corn. Average values for total percentage of hydrolyzed starch were 93.5, 85.6, 83.7 and $37.8 \%$ for the cassava scrapings, flaked corn at $310 \mathrm{~g} / \mathrm{L}$, flaked corn at $360 \mathrm{~g} / \mathrm{L}$ and ground corn, respectively. There was no difference for dry matter intake, milk protein and fat contents, microbial synthesis and plasma glucose concentration. Cassava scrapings decrease daily fat and protein productions and fat corrected milk production, with mean values of $0.40,0.45$ and $12.48 \mathrm{~kg} /$ day; $0.68,0.64$ and $19.74 \mathrm{~kg}$ /day; $0.57,0.62$ and $17.37 \mathrm{~kg}$ for cassava scrapings, flaked corn and ground corn, respectively. Average values of ruminal ammonia were lower with flaked corn or cassava scrapings, showing more active fermentation of these starch sources. Although of highest rate of starch hydrolysis, cassava scrapings altered protein metabolism with a reduction in microbial protein synthesis.
\end{abstract}

Key Words: blood parameters, cassava scrapings, flaked corn, grain processing, microbial synthesis, milk production 


\section{Introdução}

O amido representa 70 a $80 \%$ da matéria seca (MS) na maioria dos grãos de cereais e consiste na fonte primária de energia em dietas para vacas em lactação. Melhorar a utilização do amido é fundamental para aumentar a eficiência na produção de leite.

De acordo com Caldas Neto et al. (2000), a alimentação dos animais representa maior custo da atividade pecuária, principalmente quando se utiliza o milho como ingrediente energético, o qual, apesar da elevada qualidade nutricional, geralmente apresenta custo elevado. Portanto, a utilização de fontes alimentares alternativas, como resíduos agroindustriais, pode contribuir para reduzir o custo de produção e de contaminação ambiental.

O carboidrato é a fonte mais importante de energia para os microrganismos ruminais e sua utilização está diretamente relacionada à sua origem (Prado et al., 2000). Além da origem, o aumento da utilização do amido depende do processamento. O principal efeito do processamento dos grãos é a mudança no local da digestão do intestino delgado para o rúmen. Quando a digestão do amido ocorre no rúmen, aumeta a produção de ácidos graxos voláteis e de proteína microbiana (Zinn et al., 2002).

A utilização de fontes de amido de elevada degradabilidade ruminal é positiva não só por melhorar a capacidade fermentativa do rúmen, aumentando a síntese de proteína microbiana e a produção de ácidos graxos voláteis, como também por permitir economia no metabolismo energético do hospedeiro (Huntington, 1994).

O cultivo de mandioca tem grande importância econômica, uma vez que esse alimento é utilizado como principal fonte de carboidratos na alimentação humana, principalmente nos países em desenvolvimento. O Brasil é um dos maiores produtores de mandioca e possui aproximadamente 2 milhões de hectares cultivados, o que resulta em produção de 23 milhões de toneladas de raízes frescas.

A mandioca caracteriza-se por apresentar altos teores de carboidratos não-estruturais, sobretudo o amido. Marques et al. (2000) avaliaram a utilização da mandioca e de seus resíduos industriais em substituição ao milho no desempenho de novilhas em confinamento e concluíram que a substituição do milho pela mandioca e seus resíduos, embora tenha reduzido o consumo de MS, não alterou o desempenho dos animais.

Estudos relacionados à utilização da raspa de mandioca como ingrediente energético em dietas para vacas em lactação podem auxiliar na utilização deste alimento como fonte de amido em sistemas de produção de leite, que tradicionalmente utilizam milho como principal fonte energética. O estudo do desempenho e do metabolismo protéico de animais alimentados com amido de mandioca é importante na determinação das limitações e dos benefícios da utilização desta fonte energética na alimentação de ruminantes.

Objetivou-se com este trabalho avaliar a influência do fornecimento de diversas fontes e formas de processamento do amido na alimentação de vacas Holandesas em lactação, alimentadas com cana-de-açúcar como volumoso e seus efeitos sobre a digestibilidade do nitrogênio no rúmen, no intestino e no trato digestivo total, a síntese de proteína microbiana ruminal, a concentração de amônia do conteúdo ruminal, o consumo de MS, a produção e composição do leite e as concentrações de glicose e uréia no plasma.

\section{Material e Métodos}

Cinco vacas Holandesas aos 260 dias em lactação, produzindo em média 18,4 kg de leite por dia, com cânulas no rúmen e no duodeno proximal, foram distribuídas em quadrado latino $5 \times 5$ com períodos de 14 dias (10 dias de adaptação e 4 dias de coleta). Os animais foram alojados em instalações do tipo tie-stall, com acesso a comedouro e bebedouro individual.

As rações experimentais (Tabela 1), contendo aproximadamente $30 \%$ de amido, foram formuladas com $40 \%$ de cana-de-açúcar e $60 \%$ de concentrado e diferiram quanto ao processamento ou à fonte principal de amido utilizada: milho moído grosso; milho moído fino; milho floculado a $310 \mathrm{~g} / \mathrm{L}$; milho floculado a $360 \mathrm{~g} / \mathrm{L}$ ou raspa de mandioca.

Para obtenção do milho grosso, o milho foi triturado em moinho de martelos após retirada de duas facas e de todos os seis conjuntos de martelo. Para obtenção do milho fino, o milho foi processado até a espessura de fubá. O processo de floculação envolveu a passagem do milho por um conjunto de rolos laminadores após exposição a vapor por 40 a 50 minutos. As densidades ( 310 e $360 \mathrm{~g} / \mathrm{L}$ ) foram obtidas pela regulagem da distância entre os rolos e foram determinadas após o processamento pela medição do peso por unidade de volume utilizando-se proveta.

$\mathrm{O}$ alimento concentrado foi preparado previamente e misturado ao volumoso no cocho até compor uma mistura homogênea. As rações foram fornecidas à vontade, duas vezes ao dia, permitindo sobras de 5 a $10 \%$ do oferecido.

Amostras do alimento oferecido e da fração recusada foram coletadas diariamente e compostas por período e 
por animal para posteriores análises laboratoriais. Amostras do fluido ruminal $(25 \mathrm{~mL})$ foram coletadas de cada vaca em intervalos de 2 horas durante o último dia de coleta de cada período. Em seguida, foram congeladas para posterior análise de amônia (Chaney \& Marbach, 1962).

O conteúdo duodenal foi amostrado a cada 4 horas durante os quatro dias de coleta de cada período, que foi atrasada 1 hora por dia para que a amostragem fosse representada a cada hora de um período de 24 horas. As amostras foram compostas por vaca e por período e congeladas para análise posterior. Uma segunda amostra do conteúdo duodenal também foi coletada a cada amostragem, durante um dia, para separação de bactérias. Essas amostras foram centrifugadas a $2.000 \mathrm{x}$ g por 15 minutos para remoção de protozoários e partículas de alimento. O sobrenadante foi centrifugado a $18.000 \mathrm{x}$ g durante 15 minutos para separação de bactérias. Posteriormente, o pélete de bactérias foi congelado e liofilizado.

Amostras de fezes foram coletadas duas vezes ao dia nos últimos quatro dias de coleta, em horário adiantado 4 horas por dia para maior representatividade da amostragem. As amostras foram compostas por vaca por período e congeladas a $-18^{\circ} \mathrm{C}$.

Tabela 1 - Proporção dos ingredientes e composição química das rações experimentais (\% MS)

\begin{tabular}{|c|c|c|c|c|c|}
\hline \multirow[t]{2}{*}{ Ingrediente } & \multicolumn{5}{|c|}{ Fonte de amido } \\
\hline & $\begin{array}{l}\text { Milho } \\
\text { moído } \\
\text { grosso }\end{array}$ & $\begin{array}{l}\text { Milho } \\
\text { moído } \\
\text { fino }\end{array}$ & $\begin{array}{c}\text { Milho } \\
\text { floculado } \\
310 \mathrm{~g} / \mathrm{L}\end{array}$ & $\begin{array}{c}\text { Milho } \\
\text { floculado } \\
360 \mathrm{~g} / \mathrm{L}\end{array}$ & $\begin{array}{l}\text { Raspa } \\
\text { de } \\
\text { mandioca }\end{array}$ \\
\hline Cana-de-açúcar & 40,0 & 40,0 & 40,0 & 40,0 & 40,0 \\
\hline Fonte de amido & 35,6 & 35,6 & 35,6 & 35,6 & 28,4 \\
\hline Farelo de soja & 15,3 & 15,3 & 15,3 & 15,3 & 22,6 \\
\hline Caroço de algodão & 5,0 & 5,0 & 5,0 & 5,0 & 5,0 \\
\hline Premix mineral & 2,46 & 2,43 & 2,43 & 2,43 & 2,43 \\
\hline Uréia & 0,94 & 0,94 & 0,94 & 0,94 & 0,84 \\
\hline $\begin{array}{l}\text { Bicarbonato } \\
\text { de sódio }\end{array}$ & 0,7 & 0,7 & 0,7 & 0,7 & 0,7 \\
\hline \multicolumn{6}{|c|}{ Composição química ${ }^{1}$} \\
\hline PB (\%) & 16,96 & 17,27 & 15,15 & 15,88 & 16,97 \\
\hline EB (Mcal/kg) & 432 & 433 & 429 & 431 & 427 \\
\hline ELL (Mcal/kg) & 1,58 & 1,60 & 1,56 & 1,56 & 1,57 \\
\hline Amido (\%) & 29,27 & 28,06 & 31,92 & 32,54 & 30,91 \\
\hline FDN (\%) & 32,24 & 33,49 & 33,69 & 33,25 & 32,11 \\
\hline FDA (\%) & 18,40 & 18,32 & 17,49 & 17,54 & 18,99 \\
\hline EE (\%) & 2,27 & 3,02 & 2,48 & 1,97 & 1,95 \\
\hline CNF (\%) & 45,8 & 45,8 & 47,2 & 47,2 & 45,1 \\
\hline
\end{tabular}

A lignina foi utilizada como marcador interno no cálculo dos fluxos de MS do conteúdo duodenal. A digestibilidade do nitrogênio no rúmen (aparente e verdadeira) e no trato total foi calculada com base na relação entre o nutriente $\mathrm{e}$ a lignina na dieta, no conteúdo duodenal e nas fezes. Amostras das rações, das sobras, do conteúdo duodenal e das fezes foram secas em estufa de ventilação forçada (55 a $60^{\circ} \mathrm{C}$ ) por 72 horas e trituradas em moinho do tipo Wiley com peneira de crivos de $1 \mathrm{~mm}$.

As rações experimentais foram analisadas para determinação dos teores de MS, matéria mineral (MM) e proteína bruta (PB), de acordo com a AOAC (1990); fibra em detergente neutro (FDN) e fibra detergente ácido (FDA), de acordo com métodos de Van Soest et al. (1991); lignina, de acordo com Goering \& Van Soest (1970); e energia bruta, em bomba adiabática calorimétrica. A concentração de amido e as taxas de hidrólise in vitro das fontes de amido foram determinadas de acordo com Poore et al. (1991).

As amostras das sobras, do conteúdo duodenal e das fezes foram analisadas quanto aos teores de MS e nitrogênio (N), de acordo com o AOAC (1990). As amostras de bactérias foram analisadas para determinação dos teores de PB, MO e purinas (Zinn \& Owens, 1986) e o conteúdo duodenal para determinação de purinas e cálculo da síntese de proteína microbiana no rúmen.

Amostras de sangue foram coletadas da veia ou artéria coccígea, em tubos de ensaio a vácuo contendo oxalato de potássio como anticoagulante e fluoreto de sódio como antiglicolítico. O sangue foi coletado às 0 , 3, 6 e 9 h, após a alimentação da manhã, no último dia de cada período e foram centrifugadas a $3000 \mathrm{x}$ g por 15 minutos para determinação da concentração de glicose plasmática pelo método de glicose oxidase (Tietz, 1982) e uréia plasmática (Chaney \& Marbach, 1962).

As vacas foram ordenhadas duas vezes ao dia e a produção de leite foi registrada diariamente durante os quatro dias de coleta de cada período. Amostras de leite foram coletadas duas vezes ao dia, compostas e preservadas em 2-bromo-2nitropropano-1-3-diol sob refrigeração para posterior análise de proteína e gordura.

O delineamento estatístico utilizado foi o quadrado latino $5 \times 5$ e os dados foram analisados pelo procedimento GLM do pacote estatístico SAS (1999). As médias foram obtidas pelo comando LSMEANS e, para as variáveis com respostas significativas, foi aplicado o teste Tukey. Diferenças significativas foram consideradas a $5 \%$ e tendências a $10 \%$ de probabilidade. Os dados das concentrações de amônia ruminal, glicose e uréia plasmáticas foram analisados como "split plot" para detecção de interações entre tratamentos no tempo. 


\section{Resultados e Discussão}

O milho floculado apresentou maior taxa de hidrólise $(\mathrm{P}<0,05)$ do amido em comparação ao milho moído grosso (Tabela 2). Maiores taxas de hidrólise in vitro do amido processado por floculação, em comparação ao amido do grão moído ou laminado, têm sido reportadas na literatura (Chen et al., 1995; Plascencia \& Zinn, 1996; Joy et al., 1997; Yu et al.,1998).

O percentual total de amido hidrolisado para o milho moído grosso foi de 37,8\%, próximo ao de $34 \%$ observado por Yu et al. (1998), enquanto o percentual de amido hidrolisado para o milho floculado a $360 \mathrm{~g} / \mathrm{L}$ neste trabalho foi de $83,7 \%$, superior ao observado por esses autores (60\%), o que pode ser um indício de que o processo de floculação do milho utilizado neste trabalho foi mais intenso. $\mathrm{O}$ amido presente na raspa de mandioca apresentou as maiores taxas de hidrólise (Tabela 2). Os valores médios obtidos para o percentual total de amido hidrolisado foram de 37,8\% para o milho moído; 85,6\% para o milho floculado a 310 g/L; 83,7\% para o milho floculado a $360 \mathrm{~g} / \mathrm{L} ;$ e 93,5\% para a raspa de mandioca, resultados que confirmam os obtidos por Zeoula et al. (1999), que avaliaram a solubilidade e degradabilidade ruminal do amido de diversos alimentos e observaram que a degradabilidade efetiva do amido da raspa de mandioca foi $36,8 \%$ maior que a do amido do milho. Essa superioridade da raspa de mandioca provavelmente está associada à estrutura dos grânulos de amido desse alimento, que apresentam elevado conteúdo de amilopectina e ausência de associação dos grânulos de amido com a matriz protéica.

Normalmente o processamento do grão tende a reduzir os teores de gordura e proteína do leite (Theurer et al., 1999). Entretanto, neste trabalho, o consumo de MS e a porcentagem de gordura e proteína do leite não diferiram $(\mathrm{P}>0,05)$ entre as fontes de amido (Tabela 3). Houve tendência $(\mathrm{P}<0,10)$, no entanto, de a raspa de mandioca reduzir o consumo de MS, o que causou diminuição na produção e nos componentes do leite. A produção média diária de leite obtida com a raspa de mandioca pode ser considerada baixa se considerado o nível de concentrado utilizado nas rações experimentais. Entretanto, pode ser considerada compatível com o estádio

Tabela 2 - Taxa de hidrólise in vitro do amido (\% do amido total)

\begin{tabular}{lcccc}
\hline \multirow{2}{*}{ Item } & \multicolumn{4}{c}{ Fonte de amido } \\
\cline { 2 - 5 } & Milho moído & $\begin{array}{c}\text { Milho floculado } \\
310 \mathrm{~g} / \mathrm{L}\end{array}$ & $\begin{array}{c}\text { Milho floculado } \\
360 \mathrm{~g} / \mathrm{L}\end{array}$ & $\begin{array}{c}\text { Raspa } \\
\text { de }\end{array}$ \\
\hline 30 minutos & $18,76 \mathrm{a}$ & $45,59 \mathrm{~b}$ & $46,21 \mathrm{~b}$ & $77,92 \mathrm{c}$ \\
1 hora & $21,78 \mathrm{a}$ & $55,38 \mathrm{~b}$ & $56,95 \mathrm{~b}$ & $81,57 \mathrm{c}$ \\
2 horas & $25,58 \mathrm{a}$ & $66,05 \mathrm{~b}$ & $64,18 \mathrm{~b}$ & $8,87 \mathrm{c}$ \\
3 horas & $24,82 \mathrm{a}$ & $67,51 \mathrm{~b}$ & $71,23 \mathrm{~b}$ & $83,07 \mathrm{c}$ \\
4 horas & $37,78 \mathrm{a}$ & $85,61 \mathrm{~b}$ & $83,75 \mathrm{~b}$ & $93,49 \mathrm{c}$ \\
\hline
\end{tabular}

${ }^{1}$ EPM = erro-padrão da média.

a, b, c Médias seguidas de letras distintas nas linhas indicam efeito $(P<0,05)$ da fonte e do tipo de processamento do amido.

Tabela 3 - Efeito da fonte e do processamento do amido no consumo de matéria seca e na produção e composição do leite

\begin{tabular}{|c|c|c|c|c|c|c|c|}
\hline \multirow[t]{2}{*}{ Item } & \multicolumn{6}{|c|}{ Fonte de amido } & \multirow[t]{2}{*}{$\mathrm{EPM}^{2}$} \\
\hline & $\begin{array}{l}\text { Milho moído } \\
\text { grosso }\end{array}$ & $\begin{array}{l}\text { Milho moído } \\
\text { fino }\end{array}$ & $\begin{array}{l}\text { Milho floculado } \\
310 \mathrm{~g} / \mathrm{L}\end{array}$ & $\begin{array}{l}\text { Milho floculado } \\
360 \mathrm{~g} / \mathrm{L}\end{array}$ & de & $\begin{array}{l}\text { Raspa } \\
\text { mandioca }\end{array}$ & \\
\hline Ingestão de MS (kg/dia) & 19,29 & 17,27 & 17,11 & 16,37 & & 14,93 & 1,15 \\
\hline Produção de leite (kg/dia) & $20,48 a$ & $19,45 a$ & $18,95 \mathrm{ab}$ & $18,66 a b$ & & $13,81 b$ & 1,61 \\
\hline $\mathrm{LCG}^{1} 3,5$ (kg/dia) & $19,83 a$ & $19,66 \mathrm{a}$ & $17,43 a$ & $17,32 \mathrm{a}$ & & $12,48 b$ & 1,21 \\
\hline Gordura (kg/dia) & $0,67 \mathrm{a}$ & $0,69 a$ & $0,57 a$ & $0,57 a$ & & $0,40 \mathrm{~b}$ & 0,04 \\
\hline Proteína (\%) & 3,24 & 3,26 & 3,23 & 3,43 & & 3,26 & 0,19 \\
\hline Proteína (kg/dia) & $0,66 \mathrm{a}$ & $0,63 a$ & $0,61 \mathrm{a}$ & $0,64 a$ & & $0,45 b$ & 0,04 \\
\hline Prot. leite/Prot. consumida & $0,19 a b$ & $0,19 a b$ & $0,23 a$ & $0,24 a$ & & $0,17 \mathrm{~b}$ & 0,01 \\
\hline
\end{tabular}

${ }^{1}$ LCG 3,5 = produção de leite corrigida para 3,5\% de gordura.

2 EPM = erro-padrão da média.

a, b, c Médias seguidas de letras distintas nas linhas indicam efeito $(P<0,05)$ das fontes e do tipo de processamento do amido. 
médio de lactação dos animais e às condições de desconforto decorrentes das cirurgias de colocação das cânulas.

A eficiência de conversão de proteína da dieta em proteína do leite foi menor para a raspa de mandioca. Alguns autores citam que a pulverulência dos subprodutos da raiz da mandioca pode afetar negativamente a ingestão. Marques et al. (2000) avaliaram a substituição do milho pela raspa de mandioca na alimentação de novilhas em confinamento e observaram redução no consumo (11,5 × 9,1 kg MS/dia), atribuída à pulverulência do subproduto, pois observaram que logo após a ingestão houve formação de uma massa pastosa que dificultou o consumo levando os animais a permanecerem com a língua para fora. Neste trabalho não foi observado este fenômeno, provavelmente porque o elevado teor de umidade da cana-de-açúcar permitiu maior homogeneização da raspa de mandioca na ração.

Ramalho et al. (2006) substituíram o milho pela raspa de mandioca (0, 25, 50, 75 e 100\% de substituição) em rações contendo palma forrageira e silagem de sorgo como fonte de volumosos para vacas em lactação e não observaram alteração no consumo de MS. Segundo esses autores, a elevada umidade da palma forrageira facilitou a mistura da raspa de mandioca com os demais ingredientes da ração. Ao avaliarem a produção e composição do leite, esses autores obtiveram resposta linear decrescente para produção de leite, produção de leite corrigida para gordura, produção de gordura e eficiência alimentar com a substituição progressiva do milho pela raspa de mandioca.

Dihman et al. (2002) observaram maior produção e concentração de proteína do leite de animais alimentados com dietas contendo milho moído fino em relação àqueles que receberam dietas com milho moído grosso. Entretanto, neste estudo a raspa de mandioca como fonte de amido gerou redução na produção diária de gordura e de proteína do leite. A redução da produção de gordura pode estar associada à elevada taxa de hidrólise do amido da raspa de mandioca e ao seu efeito negativo sobre o $\mathrm{pH}$ ruminal. A redução do $\mathrm{pH}$ do rúmen pode interferir na biohidrogenação ruminal e aumentar o fluxo de ácidos graxos de cadeia trans para o intestino. Esses ácidos apresentam efeito negativo sobre a síntese de gordura na glândula mamária (Gaynor et al., 1994).

Os dados obtidos neste trabalho indicam que o aumento da degradabilidade do amido no rúmen melhora o metabolismo protéico do animal hospedeiro, possivelmente por permitir melhor sincronização de degradação entre as fontes energéticas e protéicas na fermentação ruminal. No caso da raspa de mandioca, a fermentação excessivamente rápida do amido diminuiu a eficiência de conversão da proteína da dieta em proteína do leite.

Houve efeito $(\mathrm{P}<0,05)$ da hora de amostragem na concentração de amônia ruminal. Entretanto, não houve interações de hora e tratamento. Desta forma, serão discutidas as médias obtidas entre os tratamentos. A concentração de amônia no rúmen foi inferior para as fontes de amido floculado e para a raspa de mandioca quando comparadas às formas moídas (Tabela 4), indicando fermentação ruminal mais ativa. A concentração média de $\mathrm{N}-\mathrm{NH}_{3}$ do fluido ruminal manteve-se acima do valor mínimo de $5 \mathrm{mg} / \mathrm{dL}$ sugerido por Satter \& Slyter (1974) como crítico para o crescimento microbiano.

A concentração média de glicose plasmática não diferiu $(\mathrm{P}>0,05)$ entre os tratamentos (Tabela 4). Estes dados estão de acordo com os obtidos por Lykos et al. (1997), que não observaram diferença nas concentrações de glicose plasmática em animais alimentados com fontes de amido de diferentes degradabilidades ruminais.

A concentração de uréia plasmática foi maior $(\mathrm{P}<0,05)$ para os animais que receberam a raspa de mandioca (Tabela 4), indicando melhor eficiência de utilização da proteína nos animais que receberam o milho moído ou floculado.

Tabela 4 - Concentrações de amônia ruminal, glicose e uréia plasmática em vacas holandesas alimentadas com diversas fontes de amido

\begin{tabular}{|c|c|c|c|c|c|c|}
\hline \multirow[t]{2}{*}{ Item } & \multicolumn{5}{|c|}{ Fonte de amido } & \multirow[t]{2}{*}{$\mathrm{EPM}^{1}$} \\
\hline & $\begin{array}{l}\text { Milho moído } \\
\text { grosso }\end{array}$ & $\begin{array}{l}\text { Milho moído } \\
\text { fino }\end{array}$ & $\begin{array}{l}\text { Milho floculado } \\
310 \mathrm{~g} / \mathrm{L}\end{array}$ & $\begin{array}{c}\text { Milho floculado } \\
360 \mathrm{~g} / \mathrm{L}\end{array}$ & $\begin{aligned} & \text { Raspa } \\
\text { de } & \text { mandioca }\end{aligned}$ & \\
\hline \multicolumn{7}{|l|}{ Rúmen } \\
\hline $\mathrm{N}-\mathrm{NH}_{3}(\mathrm{mg} / \mathrm{dL})$ & $22,17 \mathrm{a}$ & $22,5 a$ & $16,5 b c$ & $16,8 \mathrm{bc}$ & $15,3 c$ & 3,02 \\
\hline \multicolumn{7}{|l|}{ Sangue } \\
\hline Glicose (mg/dL) & 55,9 & 54,8 & 58,8 & 57,5 & 55,8 & 2,8 \\
\hline Uréia (mg/dL) & $21,9 b$ & $23,6 b$ & $21,3 b$ & $21,4 b$ & $27,6 a$ & 1,8 \\
\hline
\end{tabular}

${ }^{1}$ EPM $=$ erro-padrão da média.

a, b, c Médias seguidas de letras distintas nas linhas indicam efeito $(P<0,05)$ das fontes e do tipo de processamento do amido. 
Tabela 5 - Digestibilidade de nitrogênio $(\mathrm{N})$ de diversas fontes de amido em vacas holandesas em lactação

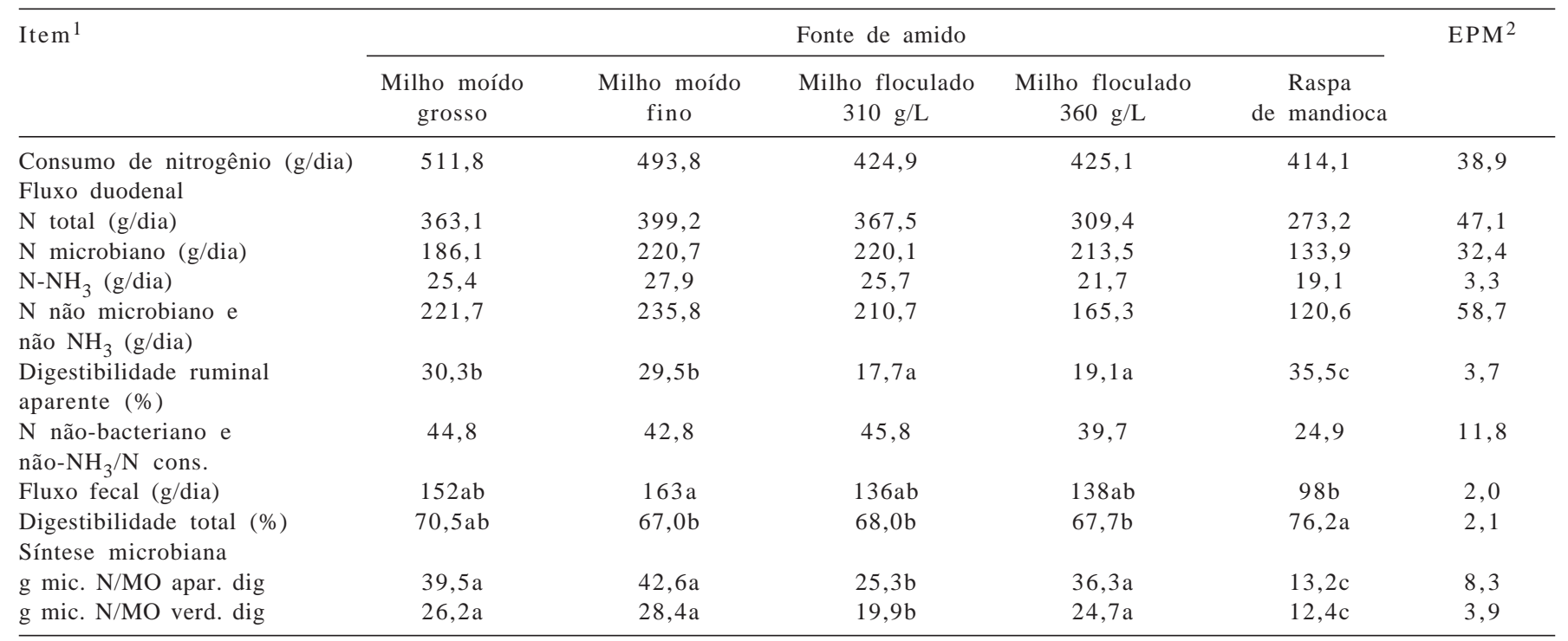

1 cons. = consumido; mic. = microbiano; apar. = aparente; dig.= digestibilidade; $\mathrm{MO}=$ matéria orgânica; verd. = verdadeira.

2 EPM = erro-padrão da média.

a, $b$, c Médias seguidas de letras distintas nas linhas indicam efeito $(P<0,05)$ das fontes e do tipo de processamento do amido.

As fontes de amido não afetaram o consumo de nitrogênio e o fluxo das frações nitrogenadas para o duodeno (Tabela 5). No entanto, houve tendência $(\mathrm{P}<0,10)$ para o milho moído fino, floculado a 310 e a floculado a $360 \mathrm{~g} / \mathrm{L}$ em aumentar o fluxo de nitrogênio microbiano para o duodeno quando comparado à raspa de mandioca e ao milho moído grosso. A menor degradabilidade ruminal do amido do milho moído grosso possivelmente diminui o substrato para fermentação e síntese de proteína bacteriana e a elevada taxa de hidrólise do amido da raspa de mandioca pode ter prejudicado a fermentação da energia e da proteína e levado a redução na eficiência microbiana total.

De acordo com Santos et al. (1998), os efeitos positivos do aumento da degradabilidade do amido sobre o teor de proteína do leite estão relacionados, possivelmente, à síntese microbiana mais intensa, que acarreta aumento no fluxo de proteína metabolizável para o intestino e melhora o perfil de aminoácidos essenciais. Entretanto, neste trabalho, o teor de proteína no leite e a síntese de proteína microbiana diminuíram $(\mathrm{P}<0,05)$ com a utilização da raspa de mandioca, apesar da alta digestibilidade ruminal do amido. O excesso de fermentação do amido pode ter causado assincronia na utilização dos produtos da fermentação da proteína e do amido para síntese de proteína microbiana.

O metabolismo protéico dos animais alimentados com a raspa de mandioca foi alterado, pois, apesar da alta degradabilidade ruminal do amido, a síntese de proteína microbiana reduziu $(\mathrm{P}<0,05)$ com o concomitante aumento da concentração de uréia plasmática (Tabela 4); sem, contudo, ter ocorrido aumento $(\mathrm{P}<0,05)$ na concentração de amônia no fluido ruminal. A ração contendo a raspa de mandioca apresentou maior $(\mathrm{P}<0,05)$ digestibilidade ruminal aparente do nitrogênio, o que indica maior perda líquida de nitrogênio do rúmen. Este fato se confirma pela maior $(\mathrm{P}<0,05)$ concentração de uréia plasmática observado para este tratamento (Tabela 4), que indica menor capacidade de retenção de nitrogênio.

\section{Conclusões}

Apesar de apresentar a maior taxa de hidrólise do amido, a raspa de mandioca altera o metabolismo protéico de vacas em lactação reduzindo a síntese de proteína microbiana. Além disso, sua utilização em rações com 40\% cana-de-açúcar como volumoso reduz a produção diária de leite e a produção de gordura e de proteína do leite. Entre as fontes de amido testadas, os menores valores médios de concentração de amônia ruminal foram obtidos com milho floculado e com raspa de mandioca, o que indica fermentação mais ativa dessas fontes de amido.

\section{Literatura Citada}

ASSOCIATION OF OFFICIAL ANALYTICAL CHEMISTS - AOAC. Official methods of analysis. 15.ed. Arlington: AOAC International, 1990. 1117p.

CALDAS NETO, S.F.; ZEOULA, L.M.; BRANCO, A.F. et al. Mandioca e resíduos das farinheiras na alimentação de ruminantes: digestibilidade total e parcial. Revista Brasileira de Zootecnia, v.29, n.6, p.2099-2108, 2000. 
CHANEY, A.L.; MARBACH, E.P. Modified reagents for determination of urea and ammonia. Clinical Chemistry, v.8, p.130-162, 1962

CHEN, K.H.; HUBER, J.T.; THEURER, C.E. et al. Effect of substituting steam-flaked sorghum for concentrate on lactation and digestion in dairy cows. Journal of Dairy Science, v.78, p.362-367, 1995.

DHIMAN, T.R.; ZAMAN, M.S.; McQUEEN, I.S. et al. Influence of corn processing and frequency of feeding on cow performance. Journal of Dairy Science, v.85, p.217-226, 2002.

GAYNOR, P.J.; ERDMAN, R.A.; TETER, B.B. et al. Milk fat yield and composition during abomasal infusion of cis or trans octadecenoates in Holstein cows. Journal of Dairy Science, v.77, p.157-165, 1994.

GOERING, H.K.; Van SOEST, P.J. Forage fiber analysis (apparatus, reagents, procedures and some applications). Washington: USDA, 1970. 20p.

HUNTINGTON, G.B. Ruminant starch utilization progress has been extensive. Feedstuffs, v.66, p.35, 1994

JOY, M.T.; DEPETERS, E.J.; FADEL, J.G. et al. Effects of corn processing on the site and extent of digestion in lactating cows. Journal of Dairy Science, v.80, p.2087-2097, 1997.

LYKOS, T.; VARGAS, G.A.; CASPER, D. Varying degradation rates of total nonstructural carbohydrates: effects on ruminal fermentation, blood metabolites, and milk production and composition in high producing Holstein cows. Journal of Dairy Science, v.80, p.3341-3355, 1997.

MARQUES, J.A.; PRADO, I.N.; ZEOULA, L.M. et al. Avaliação da mandioca e seus resíduos industriais em substituição ao milho no desempenho de novilhas confinadas. Revista Brasileira de Zootecnia, v.29, n.5, p.1528-1536, 2000.

PLASCENCIA, A.; ZINN, R.A. Influence of flake density on the feeding value of steam processed corn in diets for lactating cows. Journal of Animal Science, v.74, p.310-316, 1996.

POORE, M.H.; MOORE, J.A.; SWINGLE, R.S. et al. Wheat straw or alfalfa hay in diets with $30 \%$ neutral detergent fiber for lactating Holstein cows. Journal of Dairy Science, v.74, p.3152-3159, 1991.

PRADO, I.N.; MARTINS, A.S.; ALCALDE, C.R. et al. Desempenho de novilhas alimentadas com ração contendo milho ou casca de mandioca como fonte energética e farelo de algodão ou levedura como fonte protéica. Revista Brasileira de Zootecnia, n.29, v.1, p.278-287, 2000.

RAMALHO, R.P.; FERREIRA, M.A.; VÉRAS, A.S.C. et al Substituição do milho pela raspa de mandioca em dietas para vacas primíparas em lactação. Revista Brasileira de Zootecnia, v.35, n.3, p.1221-1227, 2006 (supl.).

STATISTICAL ANALYSIS SYSTEM - SAS. User's guide: statistics. Version 8. Cary: 1999. 965p.

SANTOS, F.A.P.; HUBER, J.T.; THEURER, C.B. Milk yield and composition of lactating cows fed steam-flaked sorghum and graded concentrations of ruminally degradable protein. Journal of Dairy Science, v.81, p.215-220, 1998.

SATTER, L.D.; SLYTER, L.L. Effect of ammonia concentration on rumen microbial protein production in vitro. British Journal of Nutrition, v.32, p.199, 1974.

THEURER, C.B.; LOZANO, O.; ALIO, A. et al. Steam-processed corn and sorghum grain flaked at different densities alter ruminal, small intestinal, and total tract digestibility of starch by steers. Journal of Animal Science, v.77, p.2828-2831, 1999.

TIETZ, N.W. Fundamental of clinical chemistry. 2.ed. Philadelphia: Saunders, 1982. 240p.

Van SOEST, P.J.; ROBERTSON, J.B.; LEWIS, B.A. Methods for dietary fiber, neutral detergent fiber and non-starch polysaccharides in relation to animal nutrition. Journal of Dairy Science, v.74, p.3583-3597, 1991.

YU, P.; HUBER, J.T.: SANTOS, F.A.P.; SIMAS, J.M. et al. Effects of ground, steam-flaked, and steam-rolled corn grains on performance of lactating cows. Journal of Dairy Science, v.81, n.3, p.777-783, 1998.

ZEOULA, L.M.; MARTINS, A.S.; ALCALDE, C.R. et al. Solubilidade e degradabilidade ruminal do amido de diferentes alimentos. Revista Brasileira de Zootecnia, v.28, n.5, p.905-912, 1999.

ZINN, R.A.; OWENS, F.N. A rapid procedure for purine measurement and its use for estimating net ruminal protein synthesis. Canadian Journal of Animal Science, v.66, p.157-166, 1986. ZINN, R.A.; OWENS, F.N.; WARE, R.A. Flaking corn: processing mechanics, quality standarts, and impacts on energy availability and performance of feedlot cattle. Journal of Animal Science, v.80, p.1145-1156, 2002. 